\title{
Pentanol isomer synthesis in engineered microorganisms
}

\author{
Anthony F. Cann • James C. Liao
}

Received: 7 July 2009 /Revised: 11 September 2009 / Accepted: 11 September 2009 / Published online: 27 October 2009

(C) The Author(s) 2009. This article is published with open access at Springerlink.com

\begin{abstract}
Pentanol isomers such as 2-methyl-1-butanol and 3-methyl-1-butanol are a useful class of chemicals with a potential application as biofuels. They are found as natural byproducts of microbial fermentations from amino acid substrates. However, the production titer and yield of the natural processes are too low to be considered for practical applications. Through metabolic engineering, microbial strains for the production of these isomers have been developed, as well as that for 1-pentanol and pentenol. Although the current production levels are still too low for immediate industrial applications, the approach holds significant promise for major breakthroughs in production efficiency.
\end{abstract}

Keywords Pentanol -2-Methyl-1-butanol .

3-Methyl-1-butanol $\cdot$ Biofuels

\section{Introduction}

Modern society relies heavily on energy, especially the energy required for the transportation of goods, services, and people. For the past century, most of our transportation energy has come from fuels derived from petroleum. However, petroleum is a non-renewable resource, and recent efforts have pushed for alternatives. A heavily produced alternative to gasoline is ethanol primarily because ethanol production is a long-established art. Yet as a fuel, ethanol does not compare well to gasoline because it has a much lower energy density (only $21 \mathrm{MJ} / \mathrm{L}$ versus about

A. F. Cann · J. C. Liao $(\square)$

Department of Chemical and Biomolecular Engineering,

University of California,

Los Angeles, CA 90095, USA

e-mail: liaoj@ucla.edu
$32 \mathrm{MJ} / \mathrm{L}$ for gasoline) and a high hygroscopicity. Pentanol isomers, as well as other higher alcohols, have a low affinity for water and an energy density of about $28 \mathrm{MJ} / \mathrm{L}$ and fit well into the current transportation infrastructure. Beyond their potential use as fuel, pentanol isomers also have a multitude of other applications.

Several reviews about microbial production of biofuels in general have been written in the past 2 years (AntizarLadislao and Turrion-Gomez 2008; Atsumi and Liao 2008; Fortman et al. 2008; Connor and Liao 2009). These reviews address a wide range of topics but are limited in their discussion about the exciting new research on pentanol production. In this paper, we take a more in-depth look at the pentanols: how they are biologically produced, how that can be improved upon, and what applications they can serve.

\section{Natural production of pentanols}

Pentanols, or amyl alcohols, have long been known to the food industry as one of many flavor compounds produced during fermentation. Studies have shown pentanols, along with their related aldehydes, acids, and esters, to be the most abundant odor and flavor components of fermented beverages (Soccol et al. 2007). In particular, 3-methyl-1-butanol (isoamyl alcohol) is often the main fermentation flavor compound after ethanol (Lurton et al. 1995; Boulton et al. 1996). Initially, the focus was on how these compounds affected the taste of fermented food products, but eventually, more research was conducted to determine the mechanism for their production.

In the beginning of the twentieth century, Ehrlich (1907) first discovered the connection between certain amino acids and the presence of higher alcohols in beer. Ehrlich's work led to the discovery of the eponymous pathway and decades of research (Sentheshanuganathan 1960; Dickinson et al. 
1997, 2000; Hazelwood et al. 2008) about how these alcohols are produced in fermentations. The Ehrlich pathway is the shortest path to higher alcohols through the direct degradation of amino acids (Fig. 1). The amino acids first undergo transamination by an amino acid aminotransferase enzyme to form 2-ketoacids, the reverse direction of the biosynthetic reaction. The next step is a decarboxylation reaction by a 2-ketoacid decarboxylase (KDC), of which the most well known is pyruvate decarboxylase for ethanol production found in a diverse array of yeast and bacteria. Decarboxylation of a 2-ketoacid yields an aldehyde and $\mathrm{CO}_{2}$, and the final reduction from aldehyde to alcohol via an alcohol dehydrogenase (ADH) is a standard fermentation reaction. For example, isoleucine added to a yeast fermentation can be converted to its 2-ketoacid, 2-keto-3-methylvalerate (KMV), which can then be decarboxylated to form 2-methyl-1-butyraldehyde, which is in turn reduced to 2-methyl-1-butanol (active amyl alcohol). Likewise, leucine is converted to 3-methyl-1-butanol, and several other amino acids can also use this pathway.

However, it is not necessary to add amino acids to a fermentation to produce these higher alcohols. The yeast and bacteria themselves synthesize all of the amino acids as well as their 2-ketoacid precursors. Yeast can produce higher alcohols from their native amino acid production pathways (Eden et al. 2001; Schoondermark-Stolk et al. 2005). In fact, the first push toward engineering the production of pentanols in microorganisms came about by exploiting this biosynthetic pathway. By using mutagenesis and selection based on the biosynthetic amino acid pathways, several groups have been able to increase higher alcohol formation in yeast (Kielland-Brandt et al. 1979; Fukuda et al. 1993; Suzzi et al. 1998). By using the toxicity of chemical analogues of the amino acids isoleucine and leucine as selection pressure, they were able to augment production of 2-methyl-1-butanol and 3-methyl-1-butanol, respectively, during fermentation. Because these studies were attempting to improve flavor rather than produce either alcohol in particular, the overall titers were still fairly low. This endogenous production and improvement in yeast can serve as a model from which to engineer the production of pentanols in other organisms.

\section{Engineered production of 2-methyl-1-butanol in Escherichia coli}

In E. coli, the KDC enzyme catalyzing the decarboxylation of higher 2-ketoacids is missing. Combined with an ADH, these two enzymes are all that is needed for conversion of 2-ketoacids in E. coli into higher alcohols. Atsumi et al. (2008b) have shown that the broad substrate range KDC from Lactococcus lactis encoded by the kivd gene is functional in $E$. coli and enables the conversion of many 2-ketoacids into alcohols, including KMV to 2-methyl-1butanol and 2-ketoisocaproate (KIC) to 3-methyl-1-butanol. The synthesis of 2-methyl-1-butanol is dependent on the 2-ketoacid precursor of the amino acid isoleucine whose biosynthetic pathway is naturally occurring in bacteria such as E. coli (Fig. 2). Thus, the isoleucine pathway, up to the common precursor $\mathrm{KMV}$, is the primary target for the engineering of 2-methyl-1-butanol production.

The first committed reaction in the biosynthesis of 2-methyl-1-butanol is the condensation of pyruvate and 2-ketobutyrate $(2 \mathrm{~KB})$, catalyzed by the enzyme acetohydroxyacid synthase (AHAS). This enzyme also catalyzes the condensation of two pyruvate molecules in the first step of valine production, though most organisms have only one isozyme to carry out this reaction. In the enterobacteria, however, there are often three isozymes present, one of which is better suited for reacting with $2 \mathrm{~KB}$ (Barak et al. 1987; Gollop et al. 1990) and thus better for the production of 2-methyl-1-butanol. Cann and Liao (2008) confirmed that overexpression of this isozyme, AHAS II, is in fact a good choice for 2-methyl-1-butanol production, especially AHAS II from Salmonella typhimurium.

For most microorganisms, the source of $2 \mathrm{~KB}$ for the AHAS reaction is the amino acid threonine. Threonine is
Fig. 1 Ehrlich degradation pathway from amino acid to alcohol. $A A T$ amino acid aminotransferase, $K D C$ 2-ketoacid decarboxylase, $A D H$ alcohol dehydrogenase, $2 K G$

2-ketoglutarate, Glu glutamate

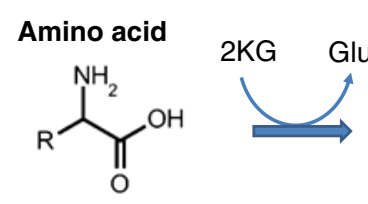<smiles>[R]C(=O)C(=O)O[Na]</smiles>
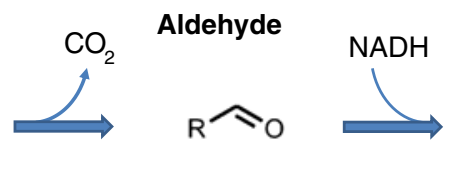

Alcohol

2-Keto-3-

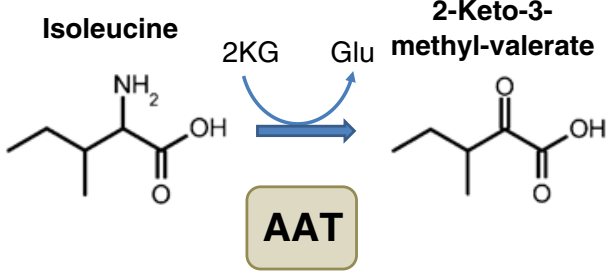

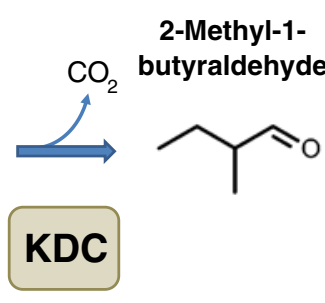

2-Methyl-1butanol 


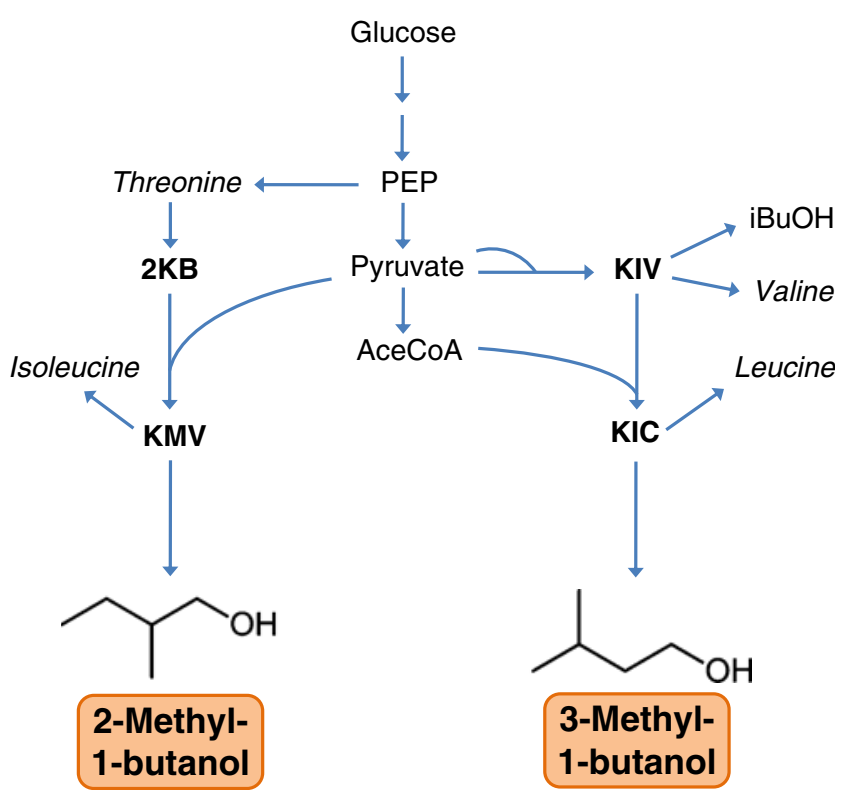

Fig. 2 Production of 2-methyl-1-butanol and 3-methyl-1-butanol from the amino acid biosynthetic pathways of isoleucine and leucine, respectively. $P E P$ phosphoenol pyruvate, $2 K B$ 2-ketobutyrate, $K I V$ 2-ketoisovalerate, $K M V$ 2-keto-3-methylvalerate, $K I C$ 2-ketoisocaproate, $\mathrm{iBuOH}$ isobutanol

converted to $2 \mathrm{~KB}$ in one reaction carried out by the enzyme threonine deaminase. Several studies have given insights to increasing threonine production in E. coli and other organisms (Shimizu et al. 1995; Lee et al. 2007), and much of this knowledge is transferrable to 2-methyl-1-butanol biosynthesis. In the case of Corynebacterium glutamicum, it was shown that a lysine-producing strain can be converted into an isoleucine-producing strain by overexpression and removal of feedback inhibition of the threonine biosynthetic pathway and threonine deaminase (Morbach et al. 1996). Recent work has validated this approach for the production of higher alcohols in E. coli, including 2-methyl-1-butanol, where the efficacy of overexpressing a feedback-resistant threonine deaminase and threonine biosynthetic operon (thrABC) with artificial transcription regulation has been clearly demonstrated (Cann and Liao 2008; Shen and Liao 2008).

Further improvement in 2-methyl-1-butanol production was achieved through gene knockouts. Many knockout strains were cultured and tested for improved 2-methyl-1butanol production, mostly genes in competing pathways and genes that lead to side product formation. However, only knockout strains leading to increased flux to threonine and $2 \mathrm{~KB}$ (metA and $t d h$ ) were significantly improved (Cann and Liao 2008). The best strain tested achieved $1.25 \mathrm{~g} / \mathrm{L}$ of 2-methyl-1-butanol with a yield of $0.17 \mathrm{~g} / \mathrm{g}$ glucose. Additional work in strain design should lead to even better 2-methyl-1-butanol production strains.
Engineered production of 3-methyl-1-butanol in $E$. coli

The leucine biosynthetic pathway in E. coli produces the 2-ketoacid precursor of 3-methyl-1-butanol, KIC (Fig. 2). Analogous to 2-methyl-1-butanol production, the expression of kivd from L. lactis facilitates the conversion of KIC to 3-methyl-1-butanol. Leucine biosynthesis also builds from the valine pathway in E. coli, consuming the precursor of valine, 2-ketoisovalerate (KIV). Previous work in isobutanol production has demonstrated the ability to produce enough KIV to enable $22 \mathrm{~g} / \mathrm{L}$ of isobutanol in E. coli cultures (Atsumi et al. 2008b). A key factor in this level of production was the expression of alsS from Bacillus subtilis coding for aceto-lactate synthase for very efficient condensation of two pyruvate molecules in the first committed step in KIV production. Another important aspect of high KIV production for isobutanol is a strain in which competing fermentation pathways are deleted, leading to an increased availability of both NADH and pyruvate. The strategies shown here to increase KIV are useful for further conversion of KIV to 3-methyl-1-butanol.

The leucine biosynthetic pathway combines KIV with acetyl coenzyme-A (acetyl-CoA) to produce KIC for 3methyl-1-butanol production. However, simply overexpressing the native leucine operon from E. coli (leuABCD) does little to divert KIV from isobutanol production (Connor and Liao 2008). It was previously demonstrated that removal of feedback inhibition of the leucine operon is effective for increasing the production of leucine in microorganisms (Gusyatiner et al. 2002). Connor and Liao (2008) showed that in addition to the expression of a feedbackresistant leucine operon, a synthetic ribosomal binding site is important for the efficient expression of the operon. These additions led to a dramatic increase in 3-methyl-1butanol production in E. coli.

Further improvement in the production of 3-methyl1-butanol can come from the deletion of competing pathways. As mentioned previously, gene knockouts of fermentation pathways such as lactate (ldhA), ethanol $(a d h E)$, acetate $(p t a)$, and succinate $(f r d B C)$, as well as knockouts of $p f l B$ and $f n r$ to increase efficiency in low oxygen conditions (Atsumi et al. 2008a), contributed to an increase in the pools of NADH, pyruvate, and acetylCoA for increased production of 3-methyl-1-butanol. Two other vital precursors, KIV and KIC, are also precursors for the transamination reaction to form the amino acids valine and leucine, respectively. Deletion of the two genes responsible for the transamination of most of the KIV and KIC, $i l v E$ and $\operatorname{tyr} B$, further increased 3methyl-1-butanol production in E. coli to a final titer of nearly $1.3 \mathrm{~g} / \mathrm{L}$ with a yield of $0.11 \mathrm{~g} / \mathrm{g}$ glucose (Connor and Liao 2008). 


\section{Isopentenol production from the terpenoid pathway}

An oxidized extension of the pentanol family, isopentenol can be found in trace amounts in the resin of certain tree species (Dewick 2002). Isopentenol is derived from the five-carbon building blocks of terpenoid synthesis, isopentenyl diphosphate (IPP) and dimethylallyl diphosphate (DMAPP; Fig. 3). There are at least two biosynthetic pathways to IPP and DMAPP common in microorganisms, one dependent on the intermediate mevalonate, made from acetyl-CoA, and found in Saccharomyces cerevisiae, and another dependent on methylerythritol phosphate, from pyruvate and glyceraldehyde-3-phosphate, and found in $E$. coli. There have been many studies concerning the engineering of these pathways for the production of higher terpenoids (Farmer and Liao 2000; Martin et al. 2003), but very little work has been done to engineer the production of isopentenol.

Isopentenol was detected at very low levels in E. coli cultures as a by-product of the overexpression of most of the native methylerythritol phosphate pathway (Rohdich et al. 2002). More recently, Withers et al. (2007) actually discovered some enzymes responsible for the direct production of isopentenol from IPP and DMAPP from $B$. subtilis. They accomplished this by screening a genomic library for the enzymatic relief of toxic levels of farnesyl diphosphate, a product of IPP and DMAPP polymerization, in $E$. coli cultures. Expression of the $n u d F$ gene from $B$. subtilis allowed the production of about $110 \mathrm{mg} / \mathrm{L}$ of isopentenol.

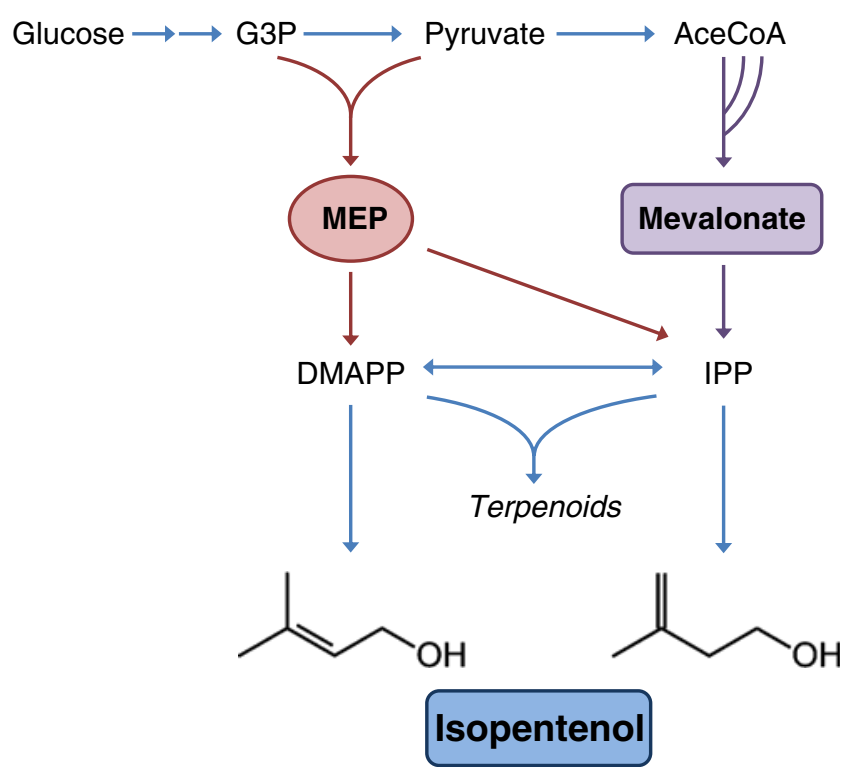

Fig. 3 Pentenol production via parallel pathways involving either the intermediate mevalonate or methylerythritol phosphate. G3P glyceraldehyde-3-phosphate, AceCoA acetyl coenzyme-A, MEP methylerythritol phosphate, DMAPP dimethylallyl diphosphate, IPP isopentenyl diphosphate

\section{1-Pentanol production using novel pathway functions}

Normal pentanol, the straight chain isomer, is a seminatural biological compound. Its presence has been detected in trace amounts in yeast fermentation (Williams et al. 1981; Mauricio et al. 1997), but the biosynthetic pathway is not well understood. Recently, however, it has been shown how 1-pentanol can be produced in microorganisms by expanding the range of substrates for known biosynthetic pathways (Zhang et al. 2008).

It was previously established that the KDC coded by kivd from L. lactis has a wide substrate range for converting 2-ketoacids into aldehydes (de la Plaza et al. 2004; Atsumi et al. 2008b), and we have already seen how well this enzyme helps in the production of two other pentanols, 2-methyl-1butanol and 3-methyl-1-butanol. However, the 2-ketoacid that would be converted to 1-pentanol, 2-ketocaproate, is not normally found in microorganisms. Interestingly, it turns out that the leucine biosynthetic pathway in E. coli (leuABCD) can also be engineered to accommodate a broad substrate range (Fig. 4).

Previous work has already shown that the leucine pathway, which normally converts KIV to KIC, can convert $2 \mathrm{~KB}$ to 2-ketovalerate, the precursor in 1-butanol production (Atsumi et al. 2008b; Shen and Liao 2008). The natural substrate for the leucine pathway is very similar to 2ketovalerate; however, overexpression in E. coli of wildtype leuABCD along with kivd produces only a small amount of 1-butanol, and no 1-pentanol is detected (Zhang et al. 2008). Protein engineering of the two promiscuous enzymes LeuA and Kivd proved to be instrumental in the production of 1-pentanol. Removal of leucine-induced feedback inhibition of LeuA first allowed 1-pentanol to be detected, and an enlargement of the Kivd substrate-binding pocket allowed a production level of $750 \mathrm{mg} / \mathrm{L}$ of 1pentanol in E. coli cultures (Zhang et al. 2008). Considering that 1-pentanol was not the final goal of this protein engineering, it seems likely that more focused work could yield even greater production of 1-pentanol in the future.

\section{Applications of pentanols}

The current push for alternative fuels has brought about our recent discussion of pentanols and other higher alcohols as potential biofuels. As discussed, pentanols have good physical properties for use as liquid transportation fuels, and they are currently used as fuel additives in gasoline blends. This section will discuss the many other applications of pentanol isomers, both current and potential.

There are a couple of ways to diversify the type of fuel that pentanols can become. For example, current biodiesel production relies mostly on methanol to esterify fatty acid 
Fig. 4 Natural and engineered reactions catalyzed by the leucine biosynthetic operon, leuABCD. $2 K V$ 2-ketovalerate, $2 \mathrm{KC}$ 2-ketocaproate, $\mathrm{PrOH}$ 1-propanol, $\mathrm{BuOH}$ 1-butanol, 3MB 3-methyl-1-butanol

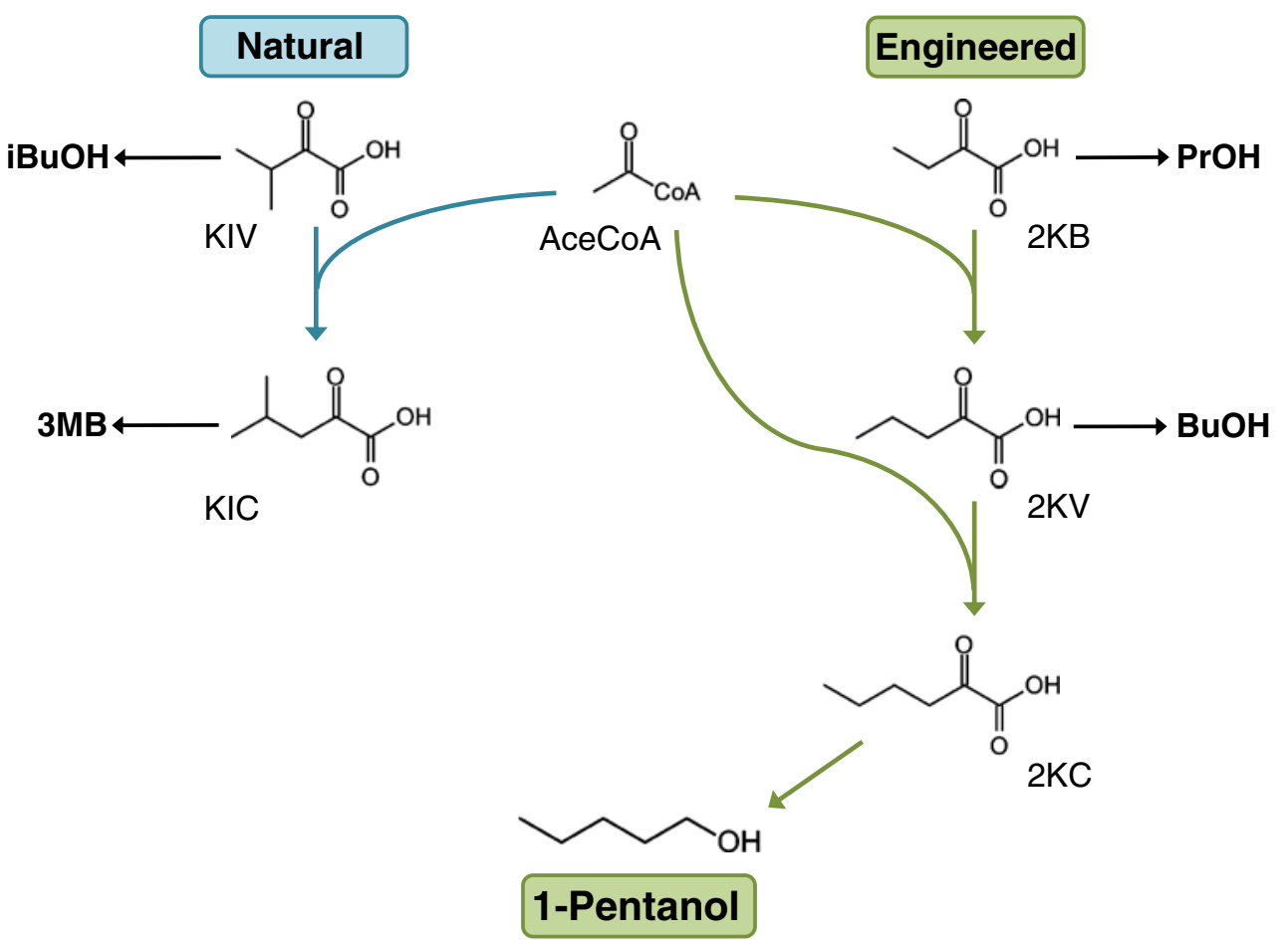

triglycerides into a diesel fuel (Gerpen 2005). However, longer chain alcohols, like pentanols, are readily used in the esterification reaction and can be preferable due to their greater fat solubility as compared to methanol (Salis et al. 2005). Another potential fuel application for pentanols and other higher alcohols could come from their polymerization to longer compounds suitable for diesel, jet fuel, or other fuels (Marchionna et al. 2001). Through a simple chemical activation of the hydroxyl group to a carbon-carbon double bond, these alcohols could be converted to a wide range of useful hydrocarbons.

Besides diesel esters, pentanols can form other esters for more applications. One of the primary flavor esters found in food fermentations is isoamyl acetate, which comes from the reaction of 3-methyl-1-butanol and acetyl-CoA. Recent work has demonstrated the viability of engineering $E$. coli for the production of isoamyl acetate from added 3-methyl1-butanol by expressing genes from $S$. cerevisiae (Vadali et al. 2004). Other work has demonstrated the potential to combine ethanol production with simultaneous expression of esterification enzymes for in vivo biodiesel production (Kalscheuer et al. 2006). This suggests that the endogenous production of 3-methyl-1-butanol demonstrated in E. coli (Connor and Liao 2008) could be combined with genes for its esterification with acetyl-CoA for engineering of the direct production of isoamyl acetate in E. coli.

A product used in the mining industry, amyl xanthate, is another useful pentanol ester. Amyl xanthate can come from any of the primary pentanol isomers, e.g., 1-pentanol, 2-methyl-1-butanol (The Dow Chemical Company 2002c;
Lappe and Hofmann 2005). Pentanol isomers are often used as solvents for chemical reaction, liquid extraction, and products such as paint and coatings (The Dow Chemical Company 2002a, b, c; Lappe and Hofmann 2005). They are especially useful as chemical intermediates or starting materials for a wide variety of products, including pharmaceuticals, antioxidants, cosmetics, herbicides, liquid crystals, dyes, flavorings, and catalysts (Gershanovskii et al. 1973; The Dow Chemical Company 2002a, b, c; Lappe and Hofmann 2005). Other applications for pentanols are additives for lubrication oil, corrosion inhibitors, and plasticizers and stabilizers for polymer plastics (The Dow Chemical Company 2002b, c; Lappe and Hofmann 2005).

Table 1 Summary of highest titers and yields for engineered pentanol production

\begin{tabular}{|c|c|c|c|}
\hline Pentanol & Titer $(g / L)$ & Yield (g/g) & Reference \\
\hline \multirow[t]{3}{*}{ 2-Methyl-1-butanol } & 1.25 & 0.17 & Cann and Liao 2008 \\
\hline & 0.37 & $\mathrm{~N} / \mathrm{A}^{\mathrm{a}}$ & Fukuda et al. 1993 \\
\hline & 0.25 & $\mathrm{~N} / \mathrm{A}^{\mathrm{a}}$ & $\begin{array}{l}\text { Kielland-Brandt } \\
\text { et al. } 1979\end{array}$ \\
\hline \multirow[t]{3}{*}{ 3-Methyl-1-butanol } & 1.28 & 0.11 & Connor and Liao 2008 \\
\hline & 0.41 & 0.008 & Watanabe et al. 1990 \\
\hline & 0.28 & 0.002 & Suzzi et al. 1998 \\
\hline \multirow[t]{2}{*}{ 1-Pentanol } & 0.75 & 0.038 & Zhang et al. 2008 \\
\hline & 0.08 & $\mathrm{~N} / \mathrm{A}^{\mathrm{a}}$ & Mauricio et al. 1997 \\
\hline Pentenol & 0.11 & 0.006 & Withers et al. 2007 \\
\hline
\end{tabular}

Not able to be determined from available data 


\section{Conclusions}

Pentanols are a useful class of compounds that have garnered increasing attention due to recent pressure to find alternatives to petroleum. While a lot of this attention is toward the fuel applications of petroleum, it should be remembered that petroleum-derived products permeate modern society. Biologically produced pentanols can be a part of the solution to moving beyond petroleum, and this review has summarized current methods of pentanol production (Table 1) and discussed many of the diverse ways that pentanols are useful.

As far as engineered production in biological systems, production of pentanols is just beginning. While long known as minor fermentation products, engineered production of pentanols has only taken place within the last 2 years. This means that much more research is required before biologically produced pentanols will be industrially relevant. The next major challenge likely to be faced in the microbial production of pentanols is the issue of toxicity. Pentanols are basically short-chain fatty alcohols and thus have a hydrophobic region of significant size. While the large hydrophobic region translates to a low solubility (about 2\%) and thus easier separation from water, it also means that these compounds are more fat-soluble and thus tend to associate in the cellular membranes of microbes. There is already much research into the toxicity of hydrophobic compounds in E. coli and other organisms (Okolo et al. 1987; Aono et al. 1994; Sikkema et al. 1995), and some solutions have been studied (Roffler et al. 1987; Aono 1998; Izak et al. 2008). As biological production of pentanols is pushed further, the issue of its toxicity will become more prominent.

There are several directions for future research into biologically engineered pentanol production. Thus far, E. coli has been the organism of choice for this production, though many of the key enzymes utilized are derived from other important and useful organisms such as yeast strains and lactobacilli. These microbes along with others can potentially offer advantages to make them better hosts for pentanol production. Further desirable research might be to include cellulose degradation directly to pentanols or even incorporate $\mathrm{CO}_{2}$ for pentanol production. The area of biologically engineered pentanol is certainly still a nascent field.

Open Access This article is distributed under the terms of the Creative Commons Attribution Noncommercial License which permits any noncommercial use, distribution, and reproduction in any medium, provided the original author(s) and source are credited.

\section{References}

Antizar-Ladislao B, Turrion-Gomez JL (2008) Second-generation biofuels and local bioenergy systems. Biofuels, Bioproducts and Biorefining 2:455-469
Aono R (1998) Improvement of organic solvent tolerance level of Escherichia coli by overexpression of stress-responsive genes. Extremophiles 2:239-248

Aono R, Kobayashi H, Joblin KN, Horikoshi K (1994) Efects of organic solvents on growth of Escherichia coli K-12. Biosci Biotechnol Biochem 58:2009-2014

Atsumi S, Liao JC (2008) Metabolic engineering for advanced biofuels production from Escherichia coli. Curr Opin Biotechnol 19:414-419

Atsumi S, Cann AF, Connor MR, Shen RC, Simth KM, Brynildsen MP, Chou KC, Hanai T, Liao JC (2008a) Metabolic engineering of Escherichia coli for 1-butanol production. Metab Eng 10:305-311

Atsumi S, Hanai T, Liao JC (2008b) Non-fermentative pathways for synthesis of branched-chain higher alcohols as biofuels. Nature 451:86-89

Barak Z, Chipman DM, Gollop N (1987) Physiological implications of the specificity of acetohydroxy acid synthase isozymes of enteric bacteria. J Bacteriol 169:3750-3756

Boulton RB, Singleton VI, Bisson IF, Kunkee RE (1996) Principles and practices of winemaking. Chapman \& Hall, Davis, pp 102-181

Cann AF, Liao JC (2008) Production of 2-methyl-1-butanol in engineered Escherichia coli. Appl Microbiol Biotechnol 81:89-98

Connor MR, Liao JC (2008) Engineering Escherichia coli for the production of 3-methyl-1-butanol. Appl Environ Microbiol 74:5769-5775

Connor MR, Liao JC (2009) Microbial production of advanced transportation fuels in non-natural hosts. Curr Opin Biotechnol 20:307-315

de la Plaza M, Fernandez de Palencia P, Pelaez C, Requena T (2004) Biochemical and molecular characterization of a-ketoisovalerate decarboxylase, an enzyme involved in the formation of aldehydes from amino acids by Lactococcus lactis. FEMS Microbiol Lett 238:367-374

Dewick PM (2002) The biosynthesis of C5-C25 terpenoid compounds. Nat Prod Rep 19:181-222

Dickinson JR, Lanterman MM, Danner DJ, Pearson BM, Sanz P, Harrison SJ, Hewlins MJ (1997) A ${ }^{13}$ C nuclear magnetic resonance investigation of the metabolism of leucine to isoamyl alcohol in Saccharomyces cerevisiae. J Biol Chem 272:26871-26878

Dickinson JR, Harrison SJ, Dickinson JA, Hewlins MJ (2000) An investigation of the metabolism of isoleucine to active amyl alcohol in Saccharomyces cerevisiae. J Biol Chem 275:10937-10942

Eden A, Van Nedervelde L, Drukker M, Benvenisty N, Debourg A (2001) Involvement of branched-chain amino acid aminotransferases in the production of fusel alcohols during fermentation in yeast. Appl Microbiol Biotechnol 55:296-300

Ehrlich F (1907) Über die Bedingungen der Fuselölbildung und über ihren Zusammenhang mit dem Eiweissaufbau der Hefe. Ber Dtsch Chem Ges 40:1027-1047

Farmer WR, Liao JC (2000) Improving lycopene production in Escherichia coli by engineering metabolic control. Nat Biotechnol 18:533-537

Fortman JL, Chhabra S, Mukhopadhyay A, Chou H, Lee TS, Steen E, Keasling JD (2008) Biofuel alternatives to ethanol: pumping the microbial well. Trends Biotechnol 26:375-381

Fukuda K, Muromachi A, Watanabe M, Asano K, Takasawa S (1993) Mutants producing high concentrations of the flavor components active amylalcohol and normal propanol in Saccharomyces cerevisiae. J Ferment Bioeng 75:288-292

Gerpen JV (2005) Biodiesel processing and production. Fuel Process Technol 86:1097-1107

Gershanovskii VS, Zelinskii YG, Lukyanov AV, Pakhomov VP, Zelvenskii YD (1973) Isoamyl alcohol as a raw material for the production of certain drug preparations. Pharm Chem J 7:236-239

Gollop N, Damri B, Chipman DM, Barak Z (1990) Physiological implications of the substrate specificities of acetohydroxy acid synthases from varied organisms. J Bacteriol 172:3444-3449 
Gusyatiner MM, Lunts MG, Koslov YI, Ivanovskaya LV, Voroshilova EB (2002) DNA coding for mutant isopropylmalate synthase L-leucine producing microorganism and method for producing L-leucine. US Patent 6,403,342

Hazelwood LA, Daran JM, van Maris AJ, Pronk JT, Dickinson JR (2008) The Ehrlich pathway for fusel alcohol production: a century of research on Saccharomyces cerevisiae metabolism. Appl Environ Microbiol 74:2259-2266

Izak P, Schwarz K, Ruth W, Bahl H, Kragl U (2008) Increased productivity of Clostridium acetobutylicum fermentation of acetone, butanol, and ethanol by pervaporation through supported ionic liquid membrane. Appl Microbiol Biotechnol 78:597-602

Kalscheuer R, Stolting T, Steinbuchel A (2006) Microdiesel: Escherichia coli engineered for fuel production. Microbiology 152:2529-2536

Kielland-Brandt MC, Petersen JGL, Mikkelsen JD (1979) Mutants in the synthesis of isoleucine in a non-mating, non-sporulating brewing strain of Saccharomyces carlsbergensis. Carlsberg Res Commun 44:27-36

Lappe P, Hofmann T (2005) Pentanols. In: Pelc H (ed) Ullmann's encyclopedia of industrial chemistry. Wiley- $\mathrm{VCH}$, Weinheim, pp $1-14$

Lee KH, Park JH, Kim TY, Kim HU, Lee SY (2007) Systems metabolic engineering of Escherichia coli for L-threonine production. Mol Syst Biol 3:149

Lurton L, Snakkers G, Rodland C, Galy B (1995) Influence of the fermentation yeast strain on the composition of wine spirits. J Sci Food Agric 67:485-491

Marchionna M, Girolamo MD, Patrini R (2001) Light olefins dimerization to high quality gasoline components. Catal Today 65:397-403

Martin VJ, Pitera DJ, Withers ST, Newman JD, Keasling JD (2003) Engineering a mevalonate pathway in Escherichia coli for production of terpenoids. Nat Biotechnol 21:796-802

Mauricio JC, Moreno J, Zea L, Ortega JM, Medina M (1997) The effects of grape must fermentation conditions on volatile alcohols and esters formed by Saccharomyces cerevisiae. J Sci Food Agric $75: 155-160$

Morbach S, Sahm H, Eggeling L (1996) L-Isoleucine production with Corynebacterium glutamicum: further flux increase and limitation of export. Appl Environ Microbiol 62:4345-4351

Okolo B, Johnston JR, Berry DR (1987) Toxicity of ethanol, nbutanol and iso-amyl alcohol in Saccharomyces cerevisiae when supplied separately and in mixtures. Biotechnol Lett 9:431-434

Roffler SR, Blanch HW, Wilke CR (1987) In-situ recovery of butanol during fermentation. Part 1: batch extractive fermentation. Bioprocess Engineering 2:1-12

Rohdich F, Hecht S, Gartner K, Adam P, Krieger C, Amslinger S, Arigoni D, Bacher A, Eisenreich W (2002) Studies on the nonmevalonate terpene biosynthetic pathway: metabolic role of IspH (LytB) protein. Proc Natl Acad Sci U S A 99:1158-1163
Salis A, Pinna M, Monduzzi M, Solinas V (2005) Biodiesel production from triolein and short chain alcohols through biocatalysis. J Biotechnol 119:291-299

Schoondermark-Stolk SA, Tabernero M, Chapman J, Ter Schure EG, Verrips CT, Verkleij AJ, Boonstra J (2005) Bat2p is essential in Saccharomyces cerevisiae for fusel alcohol production on the nonfermentable carbon source ethanol. FEMS Yeast Res 5:757-766

Sentheshanuganathan S (1960) The mechanism of the formation of higher alcohols from amino acids by Saccharomyces cerevisiae. Biochem J 74:568-576

Shen CR, Liao JC (2008) Metabolic engineering of Escherichia coli for 1-butanol and 1-propanol production via the keto-acid pathways. Metab Eng 10:312-320

Shimizu E, Oosumi T, Heima H, Tanaka T, Kurashige J, Enei H, Miwa K, Nakamori S (1995) Culture conditions for improvement of L-threonine production using a genetically self-cloned Lthreonine hyperproducing strain of Escherichia coli $\mathrm{K}-12$. Biosci Biotechnol Biochem 59:1095-1098

Sikkema J, de Bont JA, Poolman B (1995) Mechanisms of membrane toxicity of hydrocarbons. Microbiol Rev 59:201-222

Soccol CR, Medeiros ABP, Vandenberghe LPS, Woiciechowski AL (2007) Flavor compounds produced by fungi, yeast, and bacteria. In: Hui YH, Chandan RC, Clark S, Cross N, Dobbs J, Hurst WJ, Nollet LML, Shimoni E, Sinha N, Smith EB, Surapat S, Titchenal A, Toldra F (eds) Handbook of food products manufacturing. Wiley-Interscience, Hoboken, pp 179-191

Suzzi G, Romano P, Polsinelli M (1998) Isolation and characterization of mutants resistant to amino acid analogues obtained from Saccharomyces cerevisiae strains. World J Microbiol Biotechnol 14:243-246

The Dow Chemical Company (2002a) 2-Methyl butanol [brochure]. Danbury, Form 327-00038-0405

The Dow Chemical Company (2002b) $n$-Pentanol [brochure]. Danbury, Form 327-00016-0405

The Dow Chemical Company (2002c) Primary amyl alcohol [brochure]. Danbury, Form 327-00017-0405

Vadali RV, Bennett GN, San KY (2004) Applicability of CoA/acetylCoA manipulation system to enhance isoamyl acetate production in Escherichia coli. Metab Eng 6:294-299

Williams AA, Hollands TA, Tucknott OG (1981) The gas chromatographic-mass spectrometric examination of the volatiles produced by the fermentation of a sucrose solution. Z Lebensm Unters Forsch 172:377-381

Withers ST, Gottlieb SS, Lieu B, Newman JD, Keasling JD (2007) Identification of isopentenol biosynthetic genes from Bacillus subtilis by a screening method based on isoprenoid precursor toxicity. Appl Environ Microbiol 73:6277-6283

Zhang K, Sawaya MR, Eisenberg DS, Liao JC (2008) Expanding metabolism for biosynthesis of nonnatural alcohols. Proc Natl Acad Sci U S A 105:20653-20658 